\title{
Guanylate Cyclase Soluble Subunit Beta-2
}

National Cancer Institute

\section{Source}

National Cancer Institute. Guanylate Cyclase Soluble Subunit Beta-2. NCI Thesaurus.

Code C38428.

Guanylate cyclase soluble subunit beta-2 (617 aa, $70 \mathrm{kDa}$ ) is encoded by the human GUCY1B2 gene. This protein is involved in guanine nucleotide triphosphate conversion to cyclic guanine nucleotide monophosphate. 